\title{
Indicators for Sea-floor Integrity under the European Marine Strategy Framework Directive
}

\author{
Jake Rice $^{\mathrm{a}, *}$, Christos Arvanitidis ${ }^{\mathrm{b}}$, Angel Borja ${ }^{c}$, Chris Frid ${ }^{\mathrm{d}}$, Jan G. Hiddink ${ }^{\mathrm{e}}$, Jochen Krause ${ }^{f}$, \\ Pascal Lorance ${ }^{g}$, Stefán Áki Ragnarsson ${ }^{\mathrm{h}}$, Mattias Sköld', Benedetta Trabucco, Lisette Enserink ${ }^{k}$, \\ Alf Norkko'
}

\footnotetext{
a Department of Fisheries and Oceans Canada, Ecosystem Sciences Branch, 200 Kent Street, Ottawa, Ontario K1A 0E6, Canada

${ }^{b}$ Institute of Marine Biology of Crete, Hellenic Centre for Marine Research, Heraklion 71003, Crete, Greece

${ }^{c}$ AZTI-Tecnalia, Marine Research Division, Herrera Kaia, Portualdea s/n, 20110 Pasaia, Spain

${ }^{d}$ School of Biological Sciences, University of Liverpool, Crown Street, Liverpool L69 7ZB, UK

e School of Ocean Sciences, University of Wales, Bangor, Menai Bridge, Anglesey LL59 5AB, UK

${ }^{f}$ German Federal Agency for Nature Conservation, Isle of Vilm D-18581, Putbus, Germany

${ }^{g}$ Ifremer, B.P. 21105, 44311 Nantes Cedex 03, France

h Marine Research Institute, Skúlagata 4, PO Box 1390, 121 Reykjavík, Iceland

'Swedish Board of Fisheries, Institute of Marine Research, Box 4, SE-453 21 Lysekil, Sweden

${ }^{j}$ ISPRA, Central Institute for Marine Research, Via di Casalotti 300, Rome, Italy

${ }^{k}$ Ministry of Transport, Public Works and Water Management, Rijkswaterstaat Centre for Water Management, Zuiderwagenplein 2, PO Box 17, 8200 AA Lelystad, The Netherlands

I Finnish Environment Institute SYKE, Marine Spatial Planning Unit, Mechelininkatu 34a, PO Box 140, FI-00251

Helsinki, Finland
}

\author{
*: Corresponding author : Jake Rice, Tel.: +1 613990 0288; fax: +1 6139911378 ; \\ email address : Jake.Rice@dfo-mpo.gc.ca \\ arvanitidis@her.hcmr.gr ; aborja@azti.es ; chris.frid@liverpool.ac.uk ; J.Hiddink@bangor.ac.uk ; \\ jochen.krause@bfn-vilm.de ; pascal.lorance@ifremer.fr ; steara@hafro.is ; mattias.skold@fiskeriverket.se ; \\ benedetta.trabucco@isprambiente.it ; lisette.enserink@rws.nl ; alf.norkko@ymparisto.fi
}

\begin{abstract}
:
The European Marine Strategy Framework Directive (MSFD) requires European states to maintain their marine waters in "Good Environmental Status". The MSFD includes 11 descriptors of "Good Environmental Status" (GES), including "Sea-floor Integrity". This descriptor is defined as: "Sea-floor integrity is at a level that ensures that the structure and functions of the ecosystems are safeguarded and benthic ecosystems, in particular, are not adversely affected."

This contribution briefly summarizes the main conclusions of an international expert group established to review the scientific basis for making this concept operational. The experts concluded that consideration of 8 attributes of the seabed system would provide adequate information to meet requirements of the MSFD: (i) substratum, (ii) bioengineers, (iii) oxygen concentration, (iv) contaminants and hazardous substances, (v) species composition, (vi) size distribution, (vii) trophodynamics and (viii) energy flow and life history traits. The experts further concluded that "Good Environmental Status" cannot be defined exclusively as "pristine Environmental Status", but rather status when impacts of all uses were sustainable. Uses are sustainable if two conditions are met:
\end{abstract}


- the pressures associated with those uses do not hinder the ecosystem components to retain their natural diversity, productivity and dynamic ecological processes

- recovery from perturbations such that the attributes lie within their range of historical natural variation must be rapid and secure.

No single specific suite of indicators is proposed, both because no single set of indicators will meet the needs of all EU countries in all regional seas, and because according to the MSFD indicator selection is the prerogative of individual states. However, the need for conceptual consistency in assessing GES throughout European seas should be served if the selection of indicators and the integration of their information content in assessing GES follow the guidance in the report of the TG on Seafloor Integrity. This guidance is presented here in summary form.

Informed by this report European Commission selected as indicators for the Sea-floor Integrity: (i) type, abundance, biomass and areal extent of relevant biogenic substrate; (ii) extent of the seabed significantly affected by human activities for the different substrate types; (iii) presence of particularly sensitive and/or tolerant species; (iv) multi-metric indices assessing benthic community condition and functionality, such as species diversity and richness, proportion of opportunistic to sensitive species; (v) proportion of biomass or number of individuals in the macrobenthos above some specified length/size; and (vi) parameters describing the characteristics (shape, slope and intercept) of the size spectrum of the benthic community.

Keywords: Sea-floor Integrity ; Benthic indicators ; Marine Strategy Framework Directive ; Good Environmental Status 


\section{Introduction}

The European Marine Strategy Framework Directive (MSFD - EU 2008) acknowledges that the status of benthic biodiversity is an important element of the evaluation process towards a healthy ocean. Annex 3 of the MSFD includes 11 descriptors of "Good Environmental Status" (GES), one of which is "Seafloor Integrity". This descriptor is defined in the Annex as "Sea-floor integrity is at a level that ensures that the structure and functions of the ecosystems are safeguarded and benthic ecosystems, in particular, are not adversely affected". This policy recognition of benthic ecosystem quality poses several challenges for implementation.

The implementation challenges were not unique to the descriptor on Benthic Integrity. The EC asked the International Council for the Exploration of the Sea (ICES) and the Joint Research Centre of the European Commission (JRC) to oversee expert Task Groups (TG) for ten of these descriptors. These TGs were tasked to review scientific information on each descriptor, and provide expert guidance on:

- A scientific consensus on the interpretation of the terms in the descriptor;

- What constitutes GES according to the descriptor, including what are "axes of degradation";

- How to deal with issues of ecological scale;

- What are the ecological attributes of Seafloor Integrity;

- What indicators or classes of indicators for assessing status on the attributes:

o How would reference levels be set on the indicators,

o What pressures are linked to the indicators,

- How would information on the indicators be rolled up to an overall evaluation of GES for Seafloor Integrity;

- Research and monitoring needs;

This paper briefly summarizes the main conclusions of the Seafloor Integrity TG, focusing on the conclusions regarding a) selection of Indicators for the six identified attributes of "seafloor integrity", b) properties of reference points (management benchmarks) on the indicators, and c) how information from the individual indicators should be combined in the assessment of GES. The full report is available as (European Union and ICES 2010).

\section{Material and methods}

\subsection{Process for Producing the TG Report}

From nominees proposed by European member States, twelve experts were chosen, although two were unable to complete their terms on the TG. In addition both OSPAR and HELCOM appointed observers, who ensured the dialogue among TG members was accurately informed about current practices, capacities, etc of the Regional Seas Organisations which, along with their member States, would be engaged in delivering the programs under the MSFD. All experts and observers were engaged in all aspects of the work of TG, and the report was a consensus report of all participants. Work of subgroups on each attribute of seafloor integrity was coordinated by several conference calls and two meetings, with extensive sharing of drafts of text as the report sections 
developed. A Management Committee (MC) comprising all TG chairs and coordinators from ICES and JRC provided liaison between the TG and consultation meetings with EU States and stakeholders. The MC also coordinated the final round of seeking quality assurance and external feedback on each TG report, and prepared a integrative overview of the full set of reports (European Community and ICES 2010b).

\subsection{Extraction of Content of this Report.}

From the full TG report, only the final conclusions for the sections on interpretation of the descriptor, description of GES, and which attributes comprise "seafloor integrity" will be extracted. These are necessary as context for the information on selection and use of indicators. The MSFD explicitly allows individual States substantial leeway in adapting the advised GES assessment frameworks to national or regional conditions. Hence no single list of recommended indicators could be provided by the TG. Rather, the TG developed rationales as well as conclusions regarding types of indicators appropriate for each attribute. These conclusions and the rationales that underpin them are reported in more depth, as well as the TG guidance for assessing GES based on the results on the suites of indicators. In all cases the rationales and conclusions reported here adhere closely to the contents of the TG report, where the full documentation and citations to the scientific literature behind each conclusion can be found.

\section{Results}

\subsection{Major Conclusions on Context for Selection of Indicators for Seafloor Integrity.}

\subsubsection{Scientific Interpretation of the Definitions of the Descriptor and GES}

According to the MSFD, "Seafloor" includes the physical and chemical parameters of the seabed and the biotic composition of the benthic community. "Integrity" covers spatial connectedness so that the habitats are not artificially fragmented, and having the natural ecosystem processes functioning in characteristic ways. Areas of high integrity on both of these properties are resilient, so human uses may cause some perturbation without lasting or spreading harm to the ecosystems. "Structure and functions of ecosystems" is used in its conventional sense in ecological studies. "Not adversely affected" is interpreted as meaning that impacts may be occurring, but all impacts are sustainable such that natural levels of diversity, productivity, and ecosystem processes are not degraded. Although there is no single scientific consensus statement on what constitutes "good environmental status" (GES) for sea floor integrity, there also were thought to be no points of significant disagreement among experts regarding the definitions of the key terms in the descriptor, or on what constitutes gradients of degradation in environmental status. Rather, scientific challenges to implementation of the descriptor would come from uncertainties about benthic processes in the oceans, and from difficulties of sampling and monitoring on scales at which the Descriptor is to be applied.

The definition of the descriptor "Seafloor Integrity" makes clear that human uses of the ocean, and sea floor, are consistent with the goals of the MSFD, as long as those uses are sustainable and contribute to the economic and social prosperity of the EU. Consequently "good Environmental Status" cannot be defined exclusively as "pristine Environmental Status". The challenge for assessing GES is determining how large 
impacts of use can be and still be considered "sustainable". The TG concluded that uses can be considered sustainable if two conditions are met:

- the pressures associated with those uses do not hinder the ecosystem components to retain their natural diversity, productivity and dynamic ecological processes

- recovery from perturbations such that the attributes lie within their range of historical natural variation must be rapid and secure."

For some seafloor habitats and communities, recovery from perturbation would require multiple decades or more, and in such cases management should strive to prevent perturbations.

\subsubsection{Conclusions Regarding Practical Aspects of Measurement of GES}

Experts in appropriate scientific disciplines should proceed through three steps using the best available information:

(i) identify the ecological structures and functions of particular importance to a given ecosystem, using emerging methods for integrated ecosystem assessments.

(ii) review the human activities likely to occur in the area of concern and, based on the past and present levels of pressures associated with these activities, identify the ones most likely to post a threat of degrading environmental status.

(iii) for the ecosystem components (i) and pressures (ii) identified as being of greatest importance for a particular area, identify candidate indicators using established criteria for selecting indicators.

When assessing environmental status of the sea floor, it is particularly challenging to select the proper spatial and temporal scales. Many human activities cause pressures on seafloor habitats and communities. The activities may operate at different but always patchy spatial scales, both in coastal and marine areas. Consequently assessments of environmental status are almost always going to be done for areas that are a mosaic of different degrees and types of perturbations caused by human activities. Although the patchiness of the human activities and associated pressures means that the scales of initial impacts are usually also local, effects can be transported more widely by either physical transport or food-web linkages. Not only are the activities and their impacts patchy, but monitoring of the seafloor is also patchy. The few monitoring programs with relatively wide coverage generally have sampling densities that are spotty relative to the scale of features being monitored; particularly for biotic features, which are patchy on scales finer than realistic benthic monitoring programmes. These realities about patchiness of activities, impacts and sample sites have several inescapable consequences for assessments of environmental status of sea floor integrity. They mean that only rarely can monitoring be on scales that allow interpolation into reliable quantitative maps on regional scales Consequently the TG proposed a risk-based approach for evaluating GES at regional scales, It was considered feasible to map the spatial distribution of most human activities in the sea, and to tabulate both the major pressures caused by various human activities and the vulnerability of various properties of the sea floor to the various pressures. Together these steps make it realistic that spatial qualitative "risk analysis" can be conducted at regional and sub-regional scales, taking into account, inter alia:

i. the intensity or severity of the impact at the specific site being affected;

ii. the spatial extent of the impact relative to the availability of the habitat type affected; 
iii. the sensitivity/vulnerability vs the resilience of the area to the impact;

iv. the ability of the area to recover from harm, and the rate of such recovery;

$v$. the extent to which ecosystem functions may be altered by the impact; and

vi. where relevant, the timing and duration of the impact relative to the times when the area serves particular functions in the ecosystem.

The information on how risk is distributed in space provides a basis for assessing environmental status starting either with specific human activities of particular concern, or with specific attributes of the sea floor. From either starting point monitoring should be stratified along the known gradients of occurrence of the main pressures, and assessments would start with the areas of highest risk. If impacts of the highest risk areas do not violate the threshold for GES then it can be assumed that the activities are overall sustainable. If the impacts in the highest risk areas do exceed the threshold for GES, then assessments would be conducted for other risk strata, to determine how far along gradient impacts are considered not sustainable. Such an approach allows general statements to be made about environmental status at large scales while keeping monitoring requirements feasible. .

\subsubsection{Setting the Standards for GES on the Selected Indicators}

There are a few components of the sea floor which are functionally significant, easily damaged by impacts, and very slow to recovery; primarily biogenic habitats such as coral reefs. For these components, only very small levels of impact would be sustainable, and the goal of management should always to prevent impacts on those components. Similarly, for contaminants and hazardous substances it is a reasonable management standard to expect no releases into the seafloor. For both such features, the standard for GES can be pristine conditions.

For all other ecosystem features, some amount of impact is sustainable. Identifying the level of impact consistent with the standards for sustainability must consider both scientific rigour and availability of information. There are well developed methodologies for identifying reference points for sustainable use of populations exploited by fisheries, These methodologies can be applied to any population or ecosystem indicators where data are available on the ability of the ecosystem property to recover or continue to serve some important ecosystem function as a function of how much of the property is present. When information is not available on how productivity or functional value varies with the amount of an ecosystem property, less demanding methods must be used to identify the reference level for GES, often a percent of the spatio-temporal variation recorded for the indicator or in the most data poor situations an arbitrary percentage of the mean value of the indicator, over whatever space and time period is available.

\subsection{The Attributes Of Sea-Floor Integrity, and their Classes of Indicators}

\subsubsection{Substratum}

\subsubsection{Features, Pressures, and Impacts}

Four substratum types were defined based upon their physical properties: soft substratum, e.g. fine sandy and muddy sediments (particle size $<2 \mathrm{~mm}$ ), gravel substratum, e.g. cobble and pebbles (particle size from 2 to $256 \mathrm{~mm}$ ), hard substratum: igneous or sedimentary (e.g. bedrocks, rocks boulders, lava etc., particle size > 256 
$\mathrm{mm}$ ), and biogenic substratum/habitats (e.g. mussel beds, bioherms, maerl beds, cold water corals, sponge beds). In addition, topography was considered as an important feature common to all substratum types.

Of these, soft substratum types may be the most important, in terms functions and services provided to the ecosystem. Areas with soft substratum can be highly productive, sustaining a rich biotic assemblage, and habitat forming organisms can modify sediment properties to increase structural habitat complexity. Small epifaunal sessile organisms are increasingly dominant on gravel substratum types, which often have higher species richness that other substratum types under similar oceanographic conditions. The physical structure and complexity (e.g. architecture, rugosity, algal canopy) of hard substratum can be extremely variable, influencing the structure aand richness of the associated fauna. Biogenic substrata provide three-dimensional habitats for a large variety of species. In all marine areas topography is an influence on the distribution of substratum properties and the structure of associated fauna.

There is no single axis that defines a continuum from "good" status to a degraded status for the substratum. Rather, from whatever state is characteristic of a site, changes in any direction may be considered as degradation. The degree to which a particular substratum change can be defined as degradation depends on the extent to which ecosystem functions associated with the substratum are degraded. That question, in turn, can usually be better addressed with indicators of the functions being fulfilled rather than with indicators of the substratum itself, as discussed in the other subsections of 3.2.

Human Activities impacting marine substrata often differ between inshore and offshore. In inshore environments, eutrophication, dumping and extraction of sediments, port dredging, hydrocarbon exploration, land reclamation, pollution events and fishing are important whereas in offshore environments, fishing is the principal human activity affecting marine substrata with other extractive activities primarily acting on local scales. The scale of offshore environments means that considerably larger impacts are usually required to cause changes in the substratum properties large enough to have broad ecosystem consequences.

\subsubsection{Indicators}

The axis of degradation will be generally better represented by indicators of biotic attributes of the seafloor integrity, particularly the impact and state indicators in sections 3.2.2-3.2.7. Depending on the region and habitat, useful state indicators can be the proportion of an area where benthic invertebrate biomass and/or production $(P)$ are above a given percentage of a reference benthic biomass or production (Hiddink et al., 2006 a), based on direct measurement or habitat suitability modelling (Guinan et al. 2009, Roberts et al. 2005, Degraer et al. 2008, Buhl-Mortensen et al. 2009, Rattray et al. 2009, Simons and Snellen 2009). Use of multibeam echosounder (MBES) backscatter imagery (Brown and Blondel 2009) supported by ground-truthing data (Le bas and Huvenne 2009, Kenny et al. 2003, Buhl-Mortensen et al. 2009) may provide a promising way forward for producing such spatial statge indicators.

Pressures exerted by human activities and appropriateness of management interventions may be assessed directly from pressure and response indicators. For fishing activities, several pressure indicators (or data to compute them) such as fleet capacity, fishing effort and fishing mortality of fish stocks (Piet at al. 2007) are already 
available. These can be used to monitor the overall pressure generated from bottomcontacting fishing gears at regional scale and can be sensitive to management. These indicators may be maps or spatial indicators (e.g. proportion of area swept by towed gears, average frequency of trawling) aggregated at scales that are appropriate for management (Hiddink et al. 2006 a, b), taking advantage of increasing use of VMS (Vessel Monitoring System) in fleet management. Special attention should be given to the effect of scale on these pressure indicators (e.g. Piet and Quirijns 2009) and consider the possibility of "technological creep (e.g. Eigaard 2009). Similar to fishing activities, pressures from other human activities at sea including (i) the amount of marine sediments extracted, (ii) the size of the surface area licensed for extraction of sand, gravel and other material, (iii) the amount of material dredged in ports and estuaries and (iv) the amount of material dumped at sea may be estimated spatially based upon national administrations/agencies, industry sectors and stakeholders. Finally, pressure indicators for land-based activities should also be considered, where land-based activities impact estuarine, coastal and occasionally shelf areas (e.g. Lorance et al. 2009, Courrat et al. 2009. Such pressure indicators present the advantages of being easy to understand and communicate, and can be quick to respond to changes in management action (Hiddink et al. 2006b).. Response indicators relevant to the seafloor include fisheries management responses (e.g. limits on fleet capacity and fishing effort; technical and spatial measures to reduce the impact for towed gears on the seabed,

Most impact indicators of human activities on the seafloor descriptors are expected to reflect biological attributes of the seafloor. Overall functional and composition indicators of benthic communities are suitable to reflect the impact of trawling (e.g. de Juan et al. 2009, Bhagirathan et al. 2010 ), but imaging techniques also are suitable to assess impacts on the seabed when coverage is suitable (Smith et al. 2003). In the case of European waters, such tools would most likely prove more cost-effective when used for ground-truthing pressure indicators. Suitable impact indicators for extraction of marine aggregates are density/extant and depth of dredge tracks and scours detected by imaging techniques and sediment composition with respect to pre-dredge conditions or local reference sites (Boyd et al. 2005).

\subsubsection{Bio-engineers}

\subsubsection{Features, Pressures, and Impacts}

Bio-engineers are organisms that change the structure of the seafloor environment in ways not done by geophysical processes alone, either by reworking the substratum (bioturbation) e.g. by feeding, building burrows, locomotion and ventilation, or by providing structure by themselves that are used by other species. These changes affect ecosystem functions such as creating or by themselves providing shelter from predation or habitats for other organisms, protection from erosion, displacement and mixing of sediments, transport of interstitial porewater, remineralization of organic matter, and increased oxidation-reduction reactions in sediments.

GES of bioengineers are judged in relation to the function of the feature being assessed. An axis of degradation is the degree to which the functions served by the engineers are lost as the bioengineers are killed or the structures they create are damaged. The nature of the damage may vary considerably from permanent ecological damage to recovery within days. Gradients of degradation will thus vary depending on the frequency and severity of the specific disturbance, and processes affecting rate of recover. Bio- 
engineers are sensitive to direct physical disturbance causing removal or redistribution of substratum, and changes in mortality from pressures such as eutrophication and pollution. These can include pressures that change energy levels to which the seafloor is exposed, that discharge or re-distribute particulate matter, or that alter trophodynamic relationships.

\subsubsection{Indicators}

Important indicators for this attribute are metrics of abundance of organisms and extent of habitats. Guidance on how such indicators should be developed is presented in Section 3.2.4.. It is only necessary to ensure that any bio-engineers important to a given area are identified during the evaluation process. Then the species-composition guidance on calculating indicators can be applied. In some cases it would also be possible to measure the function being served. However, this is more likely to be possible for functions like nutrient regeneration through reworking sediments (where nutrient levels can be measured directly) than for functions like provision of shelter for juvenile fish (where "use of shelter" can only be measured indirectly. Pressure indicator would be areas exposed or not exposed to activities which damage or destroy the bioengineers, such as the areas not fished.

\subsubsection{Oxygen Concentration}

\subsubsection{Features, Pressures, and Impacts}

Oxygen means the concentration of dissolved oxygen in the bottom water and/or in the upper sediment layer of the seafloor. Episodic oxygen depletions are a signal that a marine system has reached a critical point of eutrophication, which, in combination with physical processes that stratify the water column, may tip the system into hypoxia. Decreasing oxygen concentration leads first to physiological and behavioural effects in benthic fauna and may culminate in mass mortality of macroscopic species when hypoxia approximates anoxic conditions. Oxygen depletion also has a clear impact on biogeochemical cycles, with hypoxia causing the release of phosphorus and ammonium from sediments. Decreases in oxygen concentration and increases hydrogen sulphide define the axis of degradation of oxygen concentration. When the demand for oxygen has exceeded its supply oxygen deficiencies may ensue, and bacteria may start to use anaerobic processes, producing toxic hydrogen sulphide. This process is accelerated by nutrient enrichment and therefore oxygen concentrations are widely used as indicator for eutrophication.

\subsubsection{Indicators}

Oxygen/Sulphide concentrations are indicators that can be measured directly and/or together with a visual image of the gradients by a profile imagery camera (Nilsson \& Rosenberg 1997). Assessments of the spatial distribution of oxygen/hydrogen sulphide concentrations in the bottom water should be conducted in critical regions and in critical seasons, e. g. during late summer and autumn, and should be conducted on a scale which enables the detection and description of the local oxygen depletion phenomena. Even short term and very local events can be early warning signals that a region has reached critical levels of nutrient loads. Indicators may be both temporal (duration of events or numbers of years with or without summer hypoxia) and spatial (extend of the depletion zones for a region or habitat type.) Additionally in those zones, indicators of 
the states of benthic communities, particularly the status of species and communities sensitive to oxygen levels inform about the duration and intensity of hypoxia (Middelburg \& Levin 2009, and COMBINE http://www.helcom.fi/groups/monas/CombineManual/en_GB/main/ ).

\subsubsection{Contaminants and Hazardous Substances}

A dedicated TG dealt comprehensively with Contaminants and Hazardous Substances as another of the descriptors of GES (ref). TG 6 did not attempt to independently address them solely for seafloor species and habitats. Rather, it noted that there is a tight link between chemical and ecological status of seafloor ecosystems. Sediments where benthic communities live are the repositories for many of the more toxic chemicals that are introduced into water bodies. Contaminated sediments represent a hazard to aquatic life through direct toxicity as well as through bioaccumulation in the food web. Consequently indicators for the Contaminants and Hazardous Substances Descriptor should ensure coverage of both the bottom substrata and sediments and the macrobenthos on the seafloor.

\subsubsection{Species Composition (Diversity, Distinctness, Complementarity/(dis)similarity, Species-area relationships)}

\subsubsection{Features, Pressures, and Impacts}

Species composition refers to the abundance, phylogenetic/taxonomic relationships, and spatial pattern of occurrence (mosaics) on many scales of the species pool that comprise a community. Species Composition includes: (a) the identity of the community units; (b) their historical relationships; (c) their ecological responses; (e) their relative and absolute patterns of abundances in space and time, and (d) the interactions among them. The attribute is also indicative of the functioning of the species in the community since their morphological and anatomical characters constrain the role they may play in the community.

Species Composition fluctuates over time and space due to environmental and anthropogenic stresses. Communities with GES are those with a few abundant species and many rare ones, and the roles that individual species play in the ecosystem are often complementary rather than competitive. Such communities have high resilience potential to moderate pressures, simply because biodiversity buffers ecosystem processes and through them the ecosystem services that can be used sustainably. The axis of degradation is from a state in which all potential niches are saturated with species or genotypes up to an azoic zone; a generalized view of a pattern originally proposed for organic enrichment gradients. A "good" species composition for a benthic unit comprises a number of species which, as a whole, take advantage of all the three dimensions of the seabed, penetrating deeply in the sediments. Only few of the species may be dominant while the majority of them are uncommon. Any pressure that can change abundance of species or increase mortality can affect Species Composition: organic and toxic pollutants, eutrophication, hypoxia, mechanical removal through operations of sand removal, waste disposal, fishing gears contacting the sea bottom, maritime operations, and building of new infrastructure on the sea bottom; etc. These may act alone or in combination, sometimes with synergistic effects. 


\subsubsection{Indicators}

There exists a variety of methods for measuring $\beta$ diversity (Magurran 2004). These can be classified into three broad categories (a) Measures which examine species turnover the difference between two or more areas of a (alpha) relative to $y$ (gamma) diversity such as Whittaker's $\beta_{w}$ measure and Wilson and Shmida's index $\beta_{T}$ (Gray 2000). (b) Measure based not only on the species numbers but also on their phylogenetics/taxonomic classification in higher levels: Average Taxonomic Distinctness $\left(\Delta^{+}\right)$and Variation in Taxonomic Distinctness $\left(\Lambda^{+}\right)$which are measure of species relatedness of different sites in relation to the species pool of the broader (bio)geographic area (Warwick and Clarke, 2001); (c) Measures of complementarity and similarity (dissimilarity) of species identity (e.g. Jaccard) and relative abundances (BrayCurtis), and may incorporate the phylogenetic/taxonomic relations of the species (Izsak and Price, 2001). Other indicators explore the species-area relationship and measure the turnover related to species accumulation with area (Harte et al., 1999; Lennon et al., 2001; Ricotta et al., 2002). Most of the above measures assume homogeneity in the sampling gear and sampling design and for most of them there is no a priori "correct" reference value which may differentiate the "good" or other levels of the environmental status, and for many indicators randomization processes must be used. These may be challenging for indicators of Taxonomic Distinctness, because the full pool of possible species that could have been represented in the sample must be specified.

\subsubsection{Size composition of the biotic community}

\subsubsection{Features, Pressures, and Impacts}

This attribute reflects either the numbers or biomass of individuals of different sizes in the community. Ecologically the size composition of a community integrates a great deal of information of about the processes underlying community dynamics, including the productivity, mortality rate, and life history strategies of the benthic species in the area, viewed in aggregate. Information about productivity is reflected in that the growth achieved by individuals in a community varies with changing productivity of a system. Size composition also reflects information about mortality rates in that in order to grow large, individuals have to live long enough to achieve their full growth potential. Information about life history strategies is reflected in a number of life history traits that vary with growth rate and maximum potential size. Community size composition reflects both the trade-offs made in coexistence of marine communities and the contributions of anthropogenic activities to productivity and mortality.

For a benthic community, an axis of degradation would be a pattern of increasing proportion of the community comprised of small individuals, and correspondingly less of the community comprised of large individuals. A "good" size composition for a benthic community is one where individuals of species capable of growing to "large" sizes are represented, and for all species a range of sizes is observed, including some individuals that have reached nearly their full growth potential. It is both a strength and a weakness of size composition that it integrates many types of human pressures. All pressures that decrease (increase) productivity (e.g. nutrient enrichment, light attenuation, thermal regimes) or increase (decrease) mortality rate (e.g. direct harvesting; impacts of fishing gears, pollutants and contaminants; winter die-offs, summer lethal temperatures, 
increases in predator abundance, decrease in prey abundance) mean fewer (more) individuals survive to the larger sizes classes attainable by the species. Hence size composition is a good reflection of aggregate impacts on productivity and mortality, but it can be difficult to sort out effects if individual pressures.

\subsubsection{Indicators}

Two major classes of indicators have been explored for size composition of marine biotic communities; proportion of numbers (or biomass) above some specified length and parameters (slope and intercept) of the "size spectrum" of the aggregate size composition data. The proportion of the community larger than some specified value is considered to be readily communicated, with the intuitive interpretation of "percent big" coinciding with the technical information the indicator class is supposed to reflect. Indicators in this class are easily calculated if sampling gear and methodology are kept consistent (Proudfoot et al. 1997, ICES 2009b) or by well calibrated remote monitoring by visual means (OSPAR nd, ICES 2009b). Selection of the critical size for this class of indicator also must be large enough to reduce noise due to recruitment variation (ICES 2008, 2009a, Greenstreet et al. in press).

The biomass size spectrum refers to the observation that over a wide range of sizes, the In(numbers) of individuals per size group decreases approximately linearly with increasing size. The community "size spectrum" which has been applied to benthic communities (Schwinghamer 1988, Duplisea 1998, Duplisea et al 2002, Dinmore and Jennings 2004, Blanchard et al 2009, Maxwell and Jennings 2006) as well as fish and pelagic invertebrate communities (Sheldon et al 1972, Pope et al. 1987, Bianchi et al. 2001, Shin et al. 2005). The intercept of the size spectrum is considered to reflect the productivity of the ecosystem, with more productive systems having higher intercepts (i.e. supporting larger numbers of individuals). The slope of the size spectrum reflects primarily community-level mortality rate and the size ratio preferences of predators relative to their prey, although differences in growth rates among communities can affect the slope slightly (Jennings et al. 2002, Jennings and Blanchard 2004, Hiddink et al. 2008, Blanchard et al. 2009). There is no a priori "right" slope or intercept for a benthic size spectrum or "percent large. Rather, trends over time or space in either or both slope and intercept provide information on whether mortality or productivity, respectively, are changing.

\subsubsection{Trophodynamics and Energy Flow}

\subsubsection{Features, Pressures and Impacts}

Trophodynamics is a complex attribute with many subcomponents: Primary and Secondary Production, Carrying Capacity, Energy Flows, and Food Web relationships. Food Web properties are a separate Descriptor in the MSFD, and a separate TG dealt thoroughly with primary production, energy, flow and food webs (ref). The TG on Seafloor Integrity stressed that the benthic component should be included fully in implementing the guidance of the Food Web TG, and considered only Secondary Production and Carrying Capacity. Secondary production is the production of biomass by heterotrophic organisms and is measured as the increase in biomass by trophic level over time. Benthic carrying capacity is the capacity of the ecosystem to support biomass of the organisms on the seabed, reflecting the food input and available space. The amount of secondary production in an ecosystem determines how much food is available for higher trophic levels. Therefore, quantification of secondary production is 
important for understanding the energy flow in food webs and carrying capacity of ecosystems. The carrying capacity of the seafloor determines how many organisms can live in this habitat and consequently the rate of ecosystem functions that can be performed and thus functioning of the ecosystem as a whole.

An axis of degradation is a gradient of declining secondary production relative to the level of secondary production previously observed for the site, or comparable sites (considering natural levels of nutrients, depth, substratum, etc). Carrying capacity is likely to be affected by the amount of energy that reaches the seafloor and the amount of space available to seafloor organisms. Human activities may directly reduce the number of organisms that live on the seafloor or alter pathways of energy from water column to seafloor. The reduction in secondary production due to exploitation or other sources of increased mortality will usually be less severe than the reduction in biomass. The most productive species tend to be least affected by exploitation, secondary production may be maintained, and occasionally even increased, by exploitation or other forms of increased community mortality even though the species composition and distribution of life history traits may be changing. Any activities that alter the seafloor physical or chemical structure, or the composition of the biotic communities may alter carrying capacity, but all effects are case specific, even for different taxa within an area.

\subsubsection{Indicators}

Carrying capacity is impossible to measure directly as it represents the potential biomass in the absence of other limiting factors rather than the actually realized biomass. As such, carrying capacity is an interesting ecological concept but has little practical operational value, and no practical and meaningful indicators were proposed. Likewise secondary productivity is very difficult to measure on all but local scales, and requires significant investment of research and monitoring effort to even produce local indicators of secondary productivity. Although the TG concluded there were no practical direct indicators of secondary productivity or carrying capacity, at least on scales needed for measuring status relative to GES, there are many indirect indicators. However, the most promising ones are already covered in the guidance provided in the other subsections of 3.2 .

The food web relationships and nutrients associated with the benthos are also important to Seafloor Integrity. However the guidance on indicators provided by the TG on the Descriptor Food Webs is considered appropriate for including those factors in evaluation GES if care is taken to include appropriate benthic components and benthic-pelagic coupling and if the benthic components of the trophodynamic relationships are taken into account when interpreting the information in food web indicators relative to GES and pressures on marine systems.

\subsubsection{Life History Traits}

\subsubsection{Features, Pressures and Impacts}

Life History Traits (LHT) are the categorisation of characteristics of the life cycle that species exhibit, i.e. growth rates, age or size or maturation, fecundity and the seasonality of life history features such as reproduction. Various combinations of these traits lead to species differing in their natural productivity, natural mortality, colonization rates. When assessing the ecological functioning of assemblages, it is the wider concept 
of the Biological Traits Analysis (BTA) that is important. As different species possess different combinations of traits, so changes in the species composition of an assemblage of species on the seabed may result in altered delivery of key ecological functions. The distribution of Biological Traits including LHT are important to GES as they reflect the status of ecosystem functioning. Changes in traits are useful because: (i) they are direct measures of the condition of the biota, (ii) they may uncover problems undetected or underestimated by other methods; and (iii) such criteria provide measurements of the progress of restoration efforts. Benthic invertebrates are used frequently as bioindicators of marine monitoring.

A GES of LHT or BT for a benthic community is habitat specific, with a "good" community comprising species with a diversity of traits. Benthic communities respond to degradations or improvements in habitat quality in a number of ways and over a variety of timeframes. Several different specific sequences have been proposed for gradients of response to increases or reductions of pressures, focusing on changes of numbers of individuals, species richness and diversity, and ratios of sensitive to tolerant species. None have yet received general acceptance.

Any pressure that alters species composition has the potential to change the distribution of biological and LH traits and so alter ecological functioning. Response in LHT and BT have been found to a variety of pressures causing changes in ocean chemistry (hypoxia and eutrophication; urban and industrial discharges; oil platform discharges; engineering works; dredging; fish and shellfish aquaculture; mine tailings; hydromorphological pressures) as well as to physical disturbances such as fishing with mobile, bottomcontacting gears.

\subsubsection{Indicators}

Marine benthic monitoring programmes tend to collect basic data on species abundance/biomass patterns in space/time. A number of indicators can be constructed from such data, based on ratios of species' abundances such as diversity and richness indices, opportunistic/sensitive species proportion (e.g. AMBI), and methods integrating several of indicators at once. For certain pressures a signal in LHT of a species may be observed before the abundance changes. To support the Water Framework Directive (ref), there is an extensive literature in the interpretation of the good status (Rosenberg et al., 2004; Muxika et al., 2007; Borja and Dauer, 2008; Borja et al., 2009b), including intercalibraiton in coastal waters (Borja et al., 2007, 2009a, Pinto et al. 2009). Some of the indicators (AMBI, M-AMBI) have been widely (e.g. Cai et al., 2003; Muniz et al., 2005; Afli et al., 2008; Bigot et al., 2008; Borja et al., 2008; Callier et al., 2008; Josefson et al., 2008; Bakalem et al., 2009), but their most extensive use is in Europe. Multivariate statistical packages have been used on species/traits data sets and in the context of measuring deviations between a reference site and the monitoring site under the Biological Traits Approach and this has been used both to assess ecological health (Bremner et al., 2003a) and to set boundaries for MPAs (Frid et al., 2008).

\subsection{On combining indicators into an overall assessment of environmental status}

The TG also considered strategies for providing an overall assessment of GES. The guidance in Section 3.2 might produce dozens to hundreds of separate indicators across the full set of attributes. Integrating the information in all these indicators into an overall assessment is not straightforward. The TG considered current practice under 
the Water Framework Directive, for provision of fisheries advice, and in environmental impact assessments. Each of these examples providing some useful insights, but none was considered to exactly parallel the needs faced with the MSFD.

The way forward must include: (a) For each region (or subregion) for which GES of the Seafloor must be assessed, experts should select an appropriate suite of classes of indicators, and more local scales, specific indicators within the classes, consistent with the guidance in the TG Report (ICES-JRC 2010); (b)The indicator selection should be used within the framework for risk-based design of monitoring and sampling regimes described in 3.1.2, reflecting both the spatial distribution of human pressures and the diversity of habitat types and disturbance regimes present in the region.

At local scales GES can be evaluated with consistent sets of indicators, indicator weightings, benchmarks, and reference levels. Scales at which such uniform approaches are meaningful can only be chosen on a case-by-case basis, using expert knowledge and input from decision-makers and informed stakeholders. Even at this scale the evaluation should not focus on some weighted combination of all indicators to provide a single number for the local area, particularly if the area is chosen to reflect a known pressure gradient. Rather it should integrate the information in the suite of indicators and benchmarks into a clear, concise, and usually multi-factorial reflection of the status of the seafloor community within the locale or along the pressure gradient.

It is neither feasible nor ecologically appropriate to specify prescriptive algorithms for evaluating GES of seafloor integrity at regional and large sub-regional scales. Specific indicators, benchmarks, and weightings are not robust enough to make best use of available and relevant information. What is needed for combining the information available on the diverse attributes of seafloor integrity is a fully specified and wellstructured process for conducting assessments of GES. Elements of such a process are provided by the Assessment of Assessments Report (UNEP and IOC-UNESCO 2009). That report elaborates how a sound assessment process should be designed, and will provide the only realistic avenue for having regular evaluations of GES of benthic integrity on regional and large sub-regional scales. The periodic (possibly but not necessarily annual) assessments may adapt practice from assessment to assessment with regard to indicators selected, weightings and benchmarks applied, and approaches to integrating local scale evaluations into regional conclusions. However full information will be provided to allow meaningful comparison of assessments over time or between areas, and for decision-makers to understand where progress is being made and where greater efforts are needed.

\section{Discussion}

The MSFD presents major challenges and opportunities for the practical use of indicators and their underlying scientific information content in supporting a balance of sustainable use of marine ecosystems for economic prosperity, and conservation of those ecosystems. It will require extensive use of indicators in evaluating Good Environmental Status. The scientific community will be challenged to make choices of indicators that provide adequately comprehensive coverage of all eight attributes of Seafloor Integrity (and the other descriptors), allow assessments on regional scales and higher, and take advantage of existing monitoring programmes to the fullest extent 
possible. The guidance provided by TG does not propose an specific suite of indicators, both because no single set of indicators will meet the needs of all EU countries in all regional seas, and because according to the MSFD indicator selection is the prerogative of individual States. However, the need for conceptual consistency in assessing GES throughout European seas should be served if the selection of indicators and the integration of their information content in assessing GES follows the guidance in the report of the TG on Seafloor Integrity. The abridged summary of that guidance that is presented here should communicate the general sense of that guidance, with details available in the much longer full report.

\section{Acknowledgements}

The authors would like to acknowledge the financial support of the EU DG Environment for travel to two workshops, and to ICES and JRC for infrastructure support.

\section{References}

Afli, A., Ayari, R., Zaabi, S., 2008. Ecological quality of some Tunisian coast and lagoon locations, by using benthic community parameters and biotic indices. Estuarine, Coastal and Shelf Science 80, 269-280.

Aller, R.C., 1994. The sedimentaryMncycle in Long Island Sound: its role as intermediate oxidant and the influence of bioturbation, $\mathrm{O} 2$, and Corg flux on diagenetic reaction balances. Journal of Marine Research 52, 259-295.

Anderson, M.J., 2001. A new method for non-parametric multivariate analysis of variance. Ecology 26, 32-46.

Aubry, A., Elliott, M., 2006. The use of environmental integrative indicators to assess seabed disturbance in estuaries and coasts: application to the Humber Estuary, UK. Marine Pollution Bulletin 53, 175-185.

Bakalem, A., Ruellet, T., Dauvin, J.C., 2009. Benthic indices and ecological quality of shallow Algeria fine sand community. Ecological Indicators 9, 395-408.

Basset, A., Sabetta, L., Sangiorgio, F., Pinna, M., Migoni, D., Fanizzi, F., Barbone, E., Galuppo, N., Fonda Umani, S., Reizopoulou, S., Nicolaidou, A., Arvanitidis, C., Moncheva, S., Trajanova, A., Georgescu, L., Beqiraj, S., 2008. Biodiversity conservation in Mediterranean and Black Sea lagoons: a trait-oriented approach to benthic invertebrate guilds. Aquatic Conservation, Marine and Freshwater Ecosystems 18S, 4-15.

Bhagirathan, U., Meenakumari, B., Jayalakshmy, K.V., Panda, S.K., Madhu, V.R., Vaghela, D.T., 2010. Impact of bottom trawling on sediment characteristics-a study along inshore waters off Veraval coast, India. Environmental Monitoring and Assessment 160, 355-369.

Bianchi, G., Gislason, H., Graham, K., Hill, L., Jin, X., Koranteng, K., ManickchandHeileman, S., Paya, I., Sainsbury, K., Sanchez, F., Zwanenburg, K., 2000. Impact of fishing on size composition and diversity of demersal fish communities. ICES Journal of Marine Science 57, 558-571.

Bigot, L., Gremare, A., Amouroux, J.-M., Frouin, E., Maire, O., Gaertner, J.C., 2008. 
Assessment of the ecological quality status of soft-bottoms in Reunion Island (tropical Southwest Indian Ocean) using AZTI marine biotic indices. Marine Pollution Bulletin 56, 704-722.

Blanchard, J.L., Jennings, S., Law, R., Castle, M.D., McCloghrie, P., Rochet, M.-J., Benoit, E., 2009. How does abundance scale with body size in coupled size-structured food webs? Journal of Animal Ecology 78, 270-280.

Borja, A., Dauer, D.M., 2008. Assessing the environmental quality status in estuarine and coastal systems: Comparing methodologies and indices. Ecological Indicators 8, 331-337.

Borja, A., Franco, J., Pérez, V., 2000. A marine biotic index to establish the ecological quality of soft-bottom benthos within European estuarine and coastal environments. Marine Pollution Bulletin 40, 1100-1114.

Borja, A., Franco, J., Valencia, V., Bald, J., Muxika, I., Belzunce, M.J., Solaun, O., 2004. Implementation of the European Water Framework Directive from the Basque Country (northern Spain): amethodological approach. Marine Pollution Bulletin 48, 209-218.

Borja, A., Josefson, A.B., Miles, A., Muxika, I., Olsgard, F., Phillips, G., Rodríguez, J.G., Rygg, B., 2007. An approach to the intercalibration of benthic ecological status assessment in the North Atlantic ecoregion, according to the European Water Framework Directive. Marine Pollution Bulletin 55, 42-52.

Borja, A., Bricker, S.B., Dauer, D.M., Demetriades, N.T., Ferreira, J.G., Forbes, A.T., Hutchings, P., Jia, X., Kenchington, R., Marques, J.C., Zhu, C., 2008. Overview of integrative tools and methods in assessing ecological integrity in estuarine and coastal systems worldwide. Marine Pollution Bulletin 56, 1519-1537.

Borja, A., Miles, A., Occhipinti-Ambrogi, A., Berg, T., 2009a. Current status of macroinvertebrate methods used for assessing the quality of European marine waters: implementing the Water Framework Directive. Hydrobiologia 633, 181-196.

Borja, A., Muxika, I., Rodríguez, J.G., 2009b. Paradigmatic responses of marine benthic communities to different anthropogenic pressures, using M-AMBI, within the European Water Framework Directive. Marine Ecology 30, 214-227.

Borja, A., Elliott, M., Carstensen, J., Heiskanen, A.-S., van de Bund, W., 2010a. Marine management-towards an integrated implementation of the European Marine Strategy Framework and the Water Framework Directives. Marine Pollution Bulletin 60 (12), 2175-2186.

Borja, Á., Dauer, D., Elliott, M., Simenstad, C., 2010b. Medium- and long-term recovery of estuarine and coastal ecosystems: patterns, rates and restoration effectiveness. Estuaries and Coasts 33, 1249-1260.

Boyd, S.E., Limpenny, D.S., Rees, H.L., Cooper, K.M., 2005. The effects of marine sand and gravel extraction on the macrobenthos at a commercial dredging site (results 6 years post-dredging). ICES Journal of Marine Science 62, 145-162.

Bremner, J., 2008. Species' traits and ecological functioning in marine conservation and management. Journal of Experimental Marine Biology and Ecology 366, 37-47.

Bremner, J., Frid, C.I.J., Rogers, S.L., 2003. Assessing marine ecosystem health: the long-term effects of fishing on functional biodiversity in North Sea benthos. Aquatic Ecosystem Health \& Management 6, 131-137.

Bremner, J., Rogers, S.I., Frid, C.I.J., 2006a. Matching biological traits to environmental conditions in marine benthic ecosystems. Journal of Marine Systems 60, 302-316.

Bremner, J., Rogers, S.I., Frid, C.I.J., 2006b. Methods for describing ecological functioning of marine benthic assemblages using biological traits analysis (BTA).

Ecological Indicators 6, 609-622.

Brey, T., 2008. Population dynamics in benthic invertebrates. In: A Virtual Handbook, Version 01.2. Alfred Wegener Institute for Polar and Marine Research, Germany, 
http://www.thomas-brey.de/science/virtualhandbook/navlog/index.html.

Brooks, E.N., Powers, J.E., Cortes, E., 2010. Analytical reference points for agestructured populations: applications to data-poor fisheries. ICES Journal of Marine Science 67, 165-175.

Brown, C.J., Blondel, P., 2009. Developments in the application of multibeam sonar backscatter for seafloor habitat mapping. Applied Acoustics 70, 1242-1247.

Buhl-Mortensen, P., Dolan, M., Buhl-Mortensen, L., 2009. Prediction of benthic biotopes on a Norwegian offshore bank using a combination of multivariate analysis and GIS classification. ICES Journal of Marine Science 66, 2026-2032.

Cai, L., Tam, N.F.Y., Wong, T.W.Y., Ma, L., Gao, Y., Wong, Y.S., 2003. Using benthic macrofauna to assess environmental quality of four intertidal mudflats in Hong Kong and Shenzhen Coast. Acta Oceanologica Sinica 22, 309-319.

Callier, M.D., McKindsey, C.W., Desrosiers, G., 2008. Evaluation of indicators used to detect mussel farm influence on the benthos: two case studies in the Magdalen Islands, Eastern Canada. Aquaculture 278, 77-88.

Cardoso, A.C., Cochrane, S., Doemer, H., Ferreira, J.G., Galgani, F., Hagebro, C., Hanke, G., Hoepffner, N., Keizer, P.D., Law, R., Olenin, S., Piet, G.J., Rice, J.C., Rogers, S.I., Swartenbroux, F., Tasker, M.L., van de Bund, W., 2010. Scientific Support to the European Commission on the Marine Strategy Framework Directive. Management Group Report. EUR 24336 EN - Joint Research Centre, Office for Official Publications of the European Communities, Luxembourg, $57 \mathrm{pp}$.

CBD, 2009. Report of the Expert Workshop on Ecological Criteria and Biogeographic Classification Systems for Marine Areas in Need of Protection. In: UNEP/CBD/EWBCS\&IMA/1/2 UNEP/Nairobi, p. 55.

Charvet, S., Kosmala, A., Statzner, B., 1998. Bio-monitoring through biological traits of benthic macroinvertebrates: perspectives for a general tool in stream management. Archives für Hydrobiologie 142, 415-432.

Charvet, S., Statzner, B., Usseglio-Polatera, P., Dumont, B., 2000. Traits of benthic macroinvertebraters in semi-natural French streams: an initial application to biomonitoring in Europe. Freshwater Biology 43, 277-296.

Clark, R.B., 1997. Marine Pollution. Clarendon Press, Oxford, p. 161.

Conley, D.J., Humborg, C., Rahm, L., Savchuk, O.P., Wulff, F., 2002. Hypoxia in the Baltic Sea and Basin-Scale changes in phosphorous and biogeochemistry. Environmental, Science \& Technology 36, 5315-5320.

Cooper, K.M., Bario Forjan, C.R.S., Defew, E., Curtis, M., Fleddum, A., Brooks, L., Paterson, D.M., 2008. Assessment of ecosystem function following marine aggregate dredging. Journal of Experimental Marine Biology and Ecology 366, 82-91.

Courrat, A., Lobry, J., Nicolas, D., Laffargue, P., Amara, R., Lepage, M., Girardin, M., Le Pape, O., 2009. Anthropogenic disturbance on nursery function of estuarine areas for marine species. Estuarine, Coastal and Shelf Science 81, 179-190. Crain, C.M., Kroeker, K., Halpern, B.S., 2008. Interactive and cumulative effects of multiple human stressors in marine systems. Ecology Letters 11, 1304-1315.

Danovaro, R., Gambi, C., Lampadariou, N., Tselepides, A., 2008. Deep-sea nematode biodiversity in the Mediterranean basin: testing for longitudinal, bathymetric and energetic gradients. Ecography 31, 231-244.

de Juan, S., Demestre, M., Thrush, S., 2009. Defining ecological indicators of trawling disturbance when everywhere that can be fished is fished: aMediterranean case study. Marine Policy 33, 472-478.

de Juan, S., Thrush, S.F., Demestre, M., 2007. Functional changes as indicators of trawling disturbance on a benthic community located in a fishing ground (NW Mediterranean Sea). Marine Ecology Progress Series 334, 117-129. 
DEFRA, 2010. Charting Progress: An Assessment of the Status of UK Waters. Department of Environment, Food, and Rural Affairs, London, $197 \mathrm{pp}$.

Degraer, S., Verfaillie, E., Willemsa, W., Adriaens, E., Vincxa, M., Van Lancker, V., 2008. Habitat suitability modelling as amapping tool for macrobenthic communities:

an example from the Belgian part of the North Sea. Continental Shelf Research 28, 369-379.

Dıaz, R.J., Rosenberg, R., 1995. Marine benthic hypoxia: a review of its ecological effects and the behavioural responses of benthic macrofauna. Oceanography and Marine Biology: An Annual Review 33, 245-303.

Diaz, R.J., Rosenberg, R., 2008. Spreading dead zones and consequences for marine ecosystems. Science 321, 926-929.

Dinmore, T.A., Jennings, S., 2004. Predicting abundance-body mass relationships in benthic infaunal communities. Marine Ecology Progress Series 276, 289-292.

Duplisea, D.E., 1998. Benthic organism biomass size-spectra in the Baltic Sea in relation to the sediment environment. Limnology and Oceanography 45, 558-568.

Duplisea, D.E., Jennings, S.L., Warr, K.J., Dinmore, T.A., 2002.Asize-based model of the impacts of bottom trawling on benthic community structure. Canadian Journal of Fisheries and Aquatic Sciences 59, 1785-1795.

Eastwood, P.D., Mills, C.M., Aldridge, J.N., Houghton, C.A., Rogers, S.I., 2007. Human activities in UK offshore waters: an assessment of direct, physical pressure on the seabed. ICES Journal of Marine Science 64, 453-462.

Eigaard, O.R., 2009. A bottom-up approach to technological development and its management implications in a commercial fishery. ICES Journal of Marine Science 66, 916-927.

Elefteriou, A., McIntyre, A. (Eds.), 2005. Methods for the Study of Marine Benthos, 3rd ed, p. 440.

European Commission, 2010. Commission Decision of 1 September 2010 on criteria and methodological standards on good environmental status of marine waters (notified under document C(2010) 5956)(2010/477/EU). Official Journal of the European Union L232, 12-24.

FAO, 2006. Stock Assessment for Fisheries Management: A Framework Guide to the Stock Assessment Tools of the Fisheries Management Programme. FAO Fisheries Technical Paper 487. FAO, Rome, 262 pp.

FAO, 2008. International Guidelines for the Management of Deep-sea Fisheries in the High Seas. FAO Fisheries Report No. 888. FAO, Rome, 37 pp.

Ferreira, J.G., Andersen, J.H., Borja, A., Bricker, S.B., Camp, J., Cardoso da Silva, M., Garcés, E., Heiskanen, A.S., Humborg, C., Ignatiades, L., Lancelot, C., Menesguen, A., Tett, P., Hoepffner, N., Claussen, U., 2010. Marine Strategy Framework Directive - Task Group 5 Report Eutrophication. EUR 24338 EN - Joint Research Centre, Office for Official Publications of the European Communities, Luxembourg, 49 pp.

Florin, A.B., Sundblad, G., Bergström, U., 2009. Characterisation of juvenile flatfish habitats in the Baltic Sea. Estuarine, Coastal and Shelf Science 82, 294-300.

Foden, J., Rogers, S.I., Jones, A.P., 2009. Recovery rates of UK seabed habitats after cessation of aggregate extraction. Marine Ecology Progress Series 390, 15-26.

Foster, S.D., Dunstan, P.K., 2009. The analysis of biodiversity using rank abundance distributions. Biometrics 87, 345-365.

Frid, C.L.J., Paramor, O.A.L., Brockington, S., Bremner, J., 2008. Incorporating ecological functioning into the designation and management of marine protected areas. Hydrobiologia 606, 69-79.

Gammeltoft, D., 2009. Progress on the Marine Strategy Framework Directive, 
www.naturvardsverket.se/upload/englis.

Glud, R.N., 2008. Oxygen dynamics of marine sediments. Marine Biology Research 4, 243-289.

Grabowski, J.H., 2004. Habitat complexity disrupts predator-prey interactions but not the trophic cascade on oyster reefs. Ecology 85, 995-1004.

Grall, J., Glémarec, M., 1997. Using biotic indices to estimate macrobenthic community perturbations in the Bay of Brest. Estuarine, Coastal and Shelf Science 44 (Suppl. A), 43-53.

Gray, J.S., 2000. The measurement of marine species diversity, with an application to the benthic fauna of the Norwegian continental shelf. Journal of Experimental Marine Biology and Ecology 250, 23-49.

Gray, J.S, Wu, R.S., Or, Y.Y., 2002. Effects of hypoxia and organic enrichment on the coastal marine environment. Marine Ecology Progress Series 238, 249-279.

Greenstreet, S.P.R., Rogers, S.I., Rice, J.C., Piet, G.J., Guirey, E.J., Fraser, H.M., Fryer, R.J., 2010. Development of the EcoQO for the North Sea fish community. ICES Journal of Marine Science 67, 1343-1355.

Guinan, J., Grehan, A.J., Dolan, M.F.J., Brown, C., 2009. Quantifying relationships between video observations of cold-water coral cover and seafloor features in Rockall Trough, west of Ireland. Marine Ecology Progress Series 375, 125-138. Hall, S.J., 1994. Physical disturbance and marine benthic communities: life in unconsolidated sediments. Oceanography and Marine Biology: An Annual Review 32, 179-239.

Halpern, B.S., Walbridge, S., Selkoe, K.A., Kappel, C.V., Micheli, F., D'Agrosa, C., Bruno, J.F., Casey, K.S., Ebert, C., Fox, H.E., Fujita, R., Heinemann, D., Lenihan, H.S., Madin, E.M.P., Perry, M.T., Selig, E.R., Spalding, M., Steneck, R., Watson, R., 2008. A global map of human impact on marine ecosystems. Science 319, 948-952.

Harte, J., Kinzig, A., Green, J., 1999. Self-similarity in the distribution and abundance of species. Science 284, 334-336.

HELCOM, 2003. The Baltic marine environment 1999-2002. In: Baltic Sea Environment Proceedings, no. 87 , p. 46.

HELCOM, 2009. Eutrophication in the Baltic Sea-an integrated thematic assessment of the effects of nutrient enrichment and eutrophication in the Baltic Sea region. In: Balt. Sea Environ. Proc. no. 115B , p. 152.

Hiddink, J.G., Jennings, S.L., Kaiser, M.J., 2006a. Indicators of the ecological impact of bottom-trawl disturbance on seabed communities. Ecosystems 9, 1190-1199.

Hiddink, J.G., Jennings, S.L., Kaiser, M.J., Queirós, A.M., Duplisea, D.E., Piet, G.J., 2006b. Cumulative impacts of seabed trawl disturbance on benthic biomass production, and species richness in different habitats. Canadian Journal of Fisheries and Aquatic Sciences 63, 721-736.

Hyland, J., Balthis, L., Karakassis, I., Magni, P., Petrov, A., Shine, J., Vestergaard, O., Warwick, R., 2005. Organic carbon content of sediments as an indicator of stress in the marine benthos. Marine Ecology Progress Series 295, 91-103.

ICES, 2008. Report of the working group on ecosystem effects of fishing activities. In: ICES CM 2008/ACOM, 41 , p. 267.

ICES, 2009a. Report of the working on ecosystem effects of fishing activities. In: ICES CM 2009/ACOM, 20 , p. 188.

ICES, 2009b. Guidelines for the study of the epibenthos of subtidal environments. In: ICES Techniques in Marine Environmental Sciences, 42 , p. 88, Contributors:

Rees, H.L., M.J.N. Bergman, S.N.R. Birchenhough, A. Borja, S.E. Boyd, C.J. Brown, L. Buhl-Mortensen, R. Callaway, D.W. Connor, K.M. Cooper, J. Davies, I. de Boois, K.D. Gilkinson, D.C. Gordon, H. Hillewaert, H. Kautsky, M. de Kluyver, I. Kröncke, 
D.S. Limpenny, W.J. Meadows, S. Parra, S.E. Pennington, E. Rachor, H.L. Rees, H. Reiss, H. Rumohr, M. Schratzberger, S. Smith, B.G. Tunberg, J.A. van Dalfsen, S. Ware, L. Watling, 2009.

Izsak, C., Price, A.R.G., 2001. Measuring $\square$-diversity using a taxonomic similarity index, and its relation to spatial scale. Marine Ecology Progress Series 215, 69-77. Jennings, S.L., Dulvy, N.K., 2005. Reference points and reference directions for sizebased indicators of community structure. ICES Journal of Marine Science 62, 397-404.

Tittensor, D.P., Baco, A.R., Brewin, P.E., Clark, M.R., Consalvey, M., Hall-Spencer, J., Ashley, A.R., Schlacher, T., Stocks, K.I., Rogers, A.D., 2009. Predicting global habitat suitability for stony corals on seamounts. Journal of Biogeography 36 , 1111-1128.

UNEP, IOC-UNESCO, 2009. An Assessment of Assessments, Findings of the Group of Experts. Start-up Phase of a Regular Process for Global Reporting and Assessment of the State of the Marine Environment including Socio-economic Aspects, 3 vols. IOC-UNESCO-Paris.

Van Hoey, G., Borja, A., Birchenough, S., Buhl-Mortensen, L., Degraer, S., Fleischer, D., Kerckhof, F., Magni, P., Muxika, I., Reiss, H., Schröder, A., Zettler, M.L., 2010. The use of benthic indicators in Europe: from the Water Framework Directive to the Marine Strategy Framework Directive. Marine Pollution Bulletin 60, 2187-2196.

Vinebrooke, R.D., Cottingham, K.L., Norberg, J., Scheffer, M., Dodson, S.L., Maberly, S.C., Sommer, U., 2004. Impacts of multiple stressors on biodiversity and ecosystem functioning: the role of species co-tolerance. Oikos 104, 451-457.

Warwick, R.M., Clarke, K.R., 2001. Practical measures of marine biodiversity based on relatedness of species. Oceanography and Marine Biology: An Annual Review

39, 207-231. 